\title{
Effects of Ingested Fresh Palm Wine on Pupil Diameter and Amplitude of Accommodation in Young Adults
}

\author{
Ugwoke, G.I. ${ }^{1}$, Esenwah, E.C. ${ }^{2}$, Ikoro, N.C. ${ }^{3}$, Azuamah, Y.C. ${ }^{4}$, Megwas, A.U. ${ }^{5}$, \\ Nwakamma, G.I. ${ }^{6}$, Nwawume, I.C. ${ }^{7}$, Okorie, M.E. ${ }^{8}$, Ogbonna, U.C. ${ }^{9}$, \\ Umunnakwe, O.L. ${ }^{10}$, Nkeremuzor, E.C ${ }^{11}$ \\ ${ }^{1-11}$ Department of Optometry, Federal University of Technology, Owerri, Nigeria \\ Corresponding Author: Ugwoke, G.I.
}

\begin{abstract}
Palm wine has long been the traditional wine of choice for most people during festive periods and social activities. This research work was done to determine the effect of ingested fresh palm wine on pupil diameter and amplitude of accommodation in young adults. Fifty (50) young adults aged between 18-35 years with a mean age of 23.46( \pm 2.54$)$ and weight ranging from $45-80 \mathrm{~kg}$ with mean weight of $61.18( \pm 8.00)$ volunteered for this work. The volunteers had normal body mass index (BMI) of between 18.5 and $25 \mathrm{~kg} / \mathrm{m} 2$. Pupil diameter in millimeters $(\mathrm{mm})$ and Amplitude of Accommodation (AA) in diopters (D) were measured before and after 30 minutes, 60 minutes and 90 minutes intake of $330 \mathrm{ml}$ of fresh palm wine containing $5.1 \%$ alcohol at the time it was consumed. Physicochemical analysis of the palm wine showed the presence of Solids, Sugar, Ascorbic acid (Vitamin C) while microbiological analysis showed the presence of yeasts. Its $\mathrm{pH}$ at the time was 6.20. Statistical analysis with SPSS version 21 showed that the mean pupil diameter before intake of fresh palm wine was $3.80( \pm 0.72)$ and mean value 30 minutes, 60 minutes and 90 minutes after intake of fresh palm wine were $3.30( \pm 0.61), 3.48( \pm 0.75)$ and $4.20( \pm 0.64)$ respectively. The mean Amplitude of accommodation before intake of fresh palm wine was 12.16( \pm 3.66$)$ and mean value 30 minutes, 60 minutes and 90 minutes after intake of fresh palm wine were 13.86( \pm 3.31$), 10.19( \pm 2.47)$ and $9.16( \pm 2.12)$ respectively. The result obtained was statistically significant using one way ANOVA at $95 \%$ confidence interval and 0.05 level of significance; $\mathrm{P}(0.00)<0.05$. The mean difference was significant at the 0.05 level. This study showed that fresh palm wine interfered with visual functions as increased pupil size and changes in AA were observed.
\end{abstract}

Keywords: Fresh palm wine, pupil diameter, amplitude of accommodation.

\section{INTRODUCTION}

Palm wine is derived from the fermented sap of a wide range of tropical plants of the palmae family, they include the oil palm (Elaeis guineensis), coconut palm (Cocus nucifera), date palm (Phoenix dactylifera), nipa palm (Nypa fruticans), kithul palm (Caryotaurens), ron palm (Borassus aethiopum), and raffia palm (Raphia hookeri) ${ }^{[1,2]}$. According to Ezeagu et. al., ${ }^{[3]}$, only Elaeis guineensis and Raphia hookeri are found in Nigeria. Fresh palm wine is known to be clear, sweet, colourless and has about 10\% - 12\% (w/v) sugar, mainly sucrose while fermented sap caused by the presence of natural microflora becomes more of alcohol as the sugar level decreases [2, 3]. After this process, the resulting liquid becomes a whitish, effervescent alcoholic beverage widely consumed in very large quantities not only in Nigeria but in West Africa ${ }^{[2,4]}$. Palm 
wine is known as 'mimbo' in Cameroon, 'nsafufuo' in Ghana, 'nkwu' or 'emu' or 'ogoro' in Nigeria and 'bandji' in Cote d'Ivoire and has been reported to be popularly consumed in West Africa by over 10 million people ${ }^{[5]}$. Alcohol is known to relax muscles all over the body; it causes the pupils to dilate as the muscles in the iris expand, causing either dilation or constriction and accommodation. Palm wine contains about $12-15 \%$ sucrose, trace amounts of glucose, fructose, maltose and raffinose, $0.23 \%$ protein, $0.02 \%$ fat, mineral matter and $5.7 \mathrm{mg} / 100 \mathrm{ml}$ of ascorbic acid ${ }^{[6]}$, $100-144 \mathrm{~g} / \mathrm{kg}$ sugar and a PH of 7.0-7.4 and traces of ethanol5. Unfermented sap is whitish with a PH of about 3.6 and alcoholic content of $3.3 \%-4 \%$ depending on the stage of fermentation at which the wine is consumed, while fermented sap contains about 4.2\%-43.0\% of alcohol ${ }^{[7]}$. They reported that within the same palm type, composition of the sap can be affected by the tapping method which causes microbial changes and this can affect the quality of the wine. According to Santiago and Ruiz ${ }^{[8]}$, high alcohols, esters, acids, aldehydes and ketones are responsible for the odorants of the palm wine. Palm wine is highly medicinal according to some researchers. It is a good source of vitamin B and C [9] which is very good for the eye. According to Ukhun et. al., ${ }^{[10]}$, vitamin $\mathrm{B}$ and $\mathrm{C}$ from palm wine aids in building the connective tissues of the body and the blood vessels in the eye which helps to prevent related eye problems such as cataracts, macular degeneration and the like. The pupil is responsible for the amount of light that is allowed into the eyes and consequently dilates or constricts to light changes in the environment ${ }^{[11,12]}$. It is the opening at the center of the eye that allows light to pass through it. Surrounded by the pupil are the iris muscles serving same purpose as the diaphragm of a camera ${ }^{[13]}$ When light enters the eye, the iris reacts by making the pupil smaller and allows less light to enter the eye. When there is decreased illumination, the iris reacts by increasing the size of the pupil to allow more light needed to see objects around ${ }^{[13]}$. Pupillary responses are caused by phasic changes in locus coeruleus (LC) activity which is noticed in norepinephrine (NE) activity. There is release of norepinephrine from the locus coeruleus ${ }^{[14]}$. Alcohol induces a biphasic effect on the higher and lower centers of the central nervous system (CNS), primarily acting on nerve cells in the brain and interfering with communication nerve cells in the peripheral nervous system (PNS) ${ }^{[15]}$. The size of a normal pupil varies from 2 to 4 $\mathrm{mm}$ in diameter under bright illumination to 4 to $8 \mathrm{~mm}$ under dark illumination among young adults ${ }^{[16]}$. The ability of the eye to focus clearly at a range of distances is known as Accommodation [17, 18, 19]. For patients to see near objects, the maximum amount of accommodation they utilize or the focusing ability they can exert is known as Amplitude of Accommodation (AA) ${ }^{[15]}$. Accommodation is among the complex triad known as the near response or the near reflex. As fixation is moved to a nearer object, a near synkinesis is evoked that includes increased accommodation, convergence and pupillary constriction. When the object is moved further away from the eyes, the opposite occurs ${ }^{[20]}$. The most widely used method to determine AA is the Push-up method as it is considered the best and easiest method in determining the AA ${ }^{[19,21]}$. Reports have claimed the effects of alcohol on the accommodative state of the eyes necessitating this study on the effects fresh palm wine would have bearing in mind that both iris and ciliary muscles receive autonomic innervations.

\section{MATERIALS AND METHODS}

The study population comprised of 50 subjects with a total of 100 eyes, within the age group of 18-35 years including, 23 males and 27 females. The study included moderate social drinkers between the ages of 18 and 35, and excluded persons with refractive errors, systemic and ocular pathologies, pregnant women, alcohol addicts, mentally and emotionally unstable 
persons, persons not willing to give consent, persons under any pharmacological treatment. A detailed case history was carried out on all the subjects, external and internal examinations were carried out to rule out subjects under the exclusion criteria. The height and weight of each subject were measured and data used to calculate their Body Mass Index (BMI). The baseline pupil diameter of both eyes was determined using a pupillometer under normal illumination. The Royal Air Force rule was used to determine the subject's baseline Amplitude of Accommodation. Monocular and Binocular AA was assessed using the Push-up to blur technique. Fresh palm wine sample of Elaeis guineensis was collected and its alcoholic content determined using distillation method. Its $\mathrm{pH}$, Sugars and yeast were also determined using standard methods. The subjects were then given $330 \mathrm{ml}$ of fresh palm wine containing $5.1 \%$ of alcohol to ingest. The pupil diameter and amplitude of accommodation of each subject were measured again after 30minutes, 60 minutes and 90 minutes of drinking fresh palm wine. Data collected was analyzed using the statistical package for social sciences (SPSS) version 21, using one way ANOVA at 0.05 level of significance and $95 \%$ confidence interval.

\section{RESULTS}

A total of fifty subjects were used for this research work. 23 (\%) males and 27 (\%) females, with a minimum age of 20 and a maximum age of 34 . The mean age and standard deviation were 23.46 and 2.54 respectively. The minimum value of the Pupil diameter before intake of fresh palm wine was 3 while the maximum value was 5. The mean pupil diameter was 3.80 with a standard deviation of 0.72 . The Amplitude of accommodation had a minimum value of 6.00 and a maximum of 20.00. The mean of the amplitude of accommodation was 12.16 while standard of deviation was 3.66.

Physicochemical and microbiological analysis of the fresh palm wine gave a $\mathrm{pH}$ of 6.2 , alcohol $5.1 \%$, Total Solids $0.27 \%$, Sugar 10\%, Ascorbic acid 5.4 $\mathrm{mg} / 100 \mathrm{ml}$ and Yeast content of $3.6 \times 104$ $\mathrm{cfu} / \mathrm{ml}$.

After the intake of fresh palm wine, the minimum value of the pupil diameter after 30 minutes was 2 while the maximum value was 4 . The mean value was 3.30 with a standard deviation of 0.61 . After 60 minutes of fresh palm wine intake, the minimum and maximum values were 2 and 5 respectively; the mean value was 3.48 while the standard deviation was 0.75 .90 minutes after intake of fresh palm wine, the minimum value of the pupil diameter was 3 with a maximum value of 5 . The mean value after 90 minutes was 4.20 with a standard deviation of 0.64 . The amplitude of accommodation as measured after 30 minutes of intake of fresh palm wine had a minimum value of 9.00 and a maximum value of 24.00 with mean value of 13.86 and a standard deviation of 3.31. After 60 minutes the minimum amplitude of accommodation was 6.50 , its maximum value was 20.00 with a mean value of 10.19 and a standard deviation of 2.47. The minimum and maximum value of the amplitude of accommodation after 90 minutes of intake of fresh palm wine was 6.00 and 18.25 respectively with a mean value of 9.16 and a standard deviation of 2.12. SPSS data analysis using the one-way ANOVA at 0.05 level of significance showed that Pupil diameter and Accommodation before and after 30, 60 and 90 minutes of fresh palm wine consumption is not the same. $[\mathrm{P}(0.00)<0.05]$. Results showed a marked increase in pupil diameter with subsequent decrease in amplitude of accommodation after intake of fresh palm wine.

\section{DISCUSSION}

Palm wine is a traditional beverage commonly consumed fresh or fermented. The benefits of palm wine is optimized by consuming the fresh sap as the fermented sap contains higher levels of alcohol and can cause harm to the body, especially the 
liver ${ }^{[7]}$ it has been shown to also affect visual functions ${ }^{[15,22]}$. The alcoholic content found in the fresh palm wine was $5.1 \%$. The result differed from most researchers who found the alcohol content of freshly tapped palm wine to fermented palm wine to be about $4.2-43.0 \%{ }^{[7]}$. Similarly, in another work by Megwas et al ${ }^{[22]}$ to study the effect of palm wine and beer on accommodative tests of subjects, the palm wine used was obtained from a local market and the alcohol content was found to be $6 \%$. The differences in the percentage of alcohol content of freshly tapped palm wine could be due to the continuous fermentation process going on as the yeast content multiplies and converts the sugar contained in the palm wine to ethanol ${ }^{[2,8]}$. Yeast count contained in the fresh palm wine sample was found to be $3.6 \mathrm{x} 104 \mathrm{cfu} / \mathrm{ml}$. This result supported the work of Karamoko et al ${ }^{[2]}$ whose work showed lower loads of yeasts on the first day of tapping.

The age group 18-35 years comprised of young adults who are visually active. This group of people is known to also indulge more in alcohol. Among the 50 volunteers, there were more females than males. A positive correlation between pupil diameter and palm wine could be because alcohol is readily absorbed in females than in males ${ }^{[23]}$. From findings in the research work, the mean pupil diameter decreased slightly when compared to the values noted 30 minutes and 60 minutes after intake of fresh palm wine. The baseline mean pupil diameter was $3.80( \pm 0.72)$ while the mean pupil diameter 30 minutes and 60 minutes after intake of fresh palm wine were 3.30 $( \pm 0.61)$ and $3.48( \pm 0.75)$ respectively. This result showed a slight temporal miosis after ingestion of fresh palm wine. This is in accordance with the work of Igwe ${ }^{[24]}$, who discovered slight miosis which was still within normal range after bolus ingestion of
Eleais guneensis, though there was no stipulated time frame.

A rise in the mean value of pupil diameter after 90 minutes intake of palm wine was noted. The value increased to $4.20 \pm 0.64$ indicating a slight dilation after miosis. This might be so, owing to the fact that alcohol causes muscle relaxation in the body ${ }^{[25]}$. Pupil dilation after intake of fresh palm wine is also in line with the work of Castro et al ${ }^{[26]}$. They determined that the influence of alcohol on subjects and their results showed increase in pupil size. The mean values of Amplitude of accommodation before, 30 minutes, 60 minutes and 90 minutes after intake of palm wine were recorded. The mean AA showed a rise after 30 minutes of fresh palm wine intake. The value increased from the baseline value of $12.16( \pm 3.66)$ to 13.86 $( \pm 3.31)$. This could have occurred due to the slight miosis of the pupil after 30 minutes of fresh palm wine intake. This result was also in line with Igwe et al ${ }^{[24]}$, whose work on the effect of bolus ingestion of palm wine showed a $12.5 \%$ rise in AA. Mean values after 60 minutes and 90 minutes of fresh palm wine intake were $10.19 \pm 2.27$ and $9.16 \pm 2.12$ respectively. This result is in line with many research works on the effects of alcoholic beverages on the eyes. Azuamah et al ${ }^{[15]}$, and Megwas et al ${ }^{[22]}$, got related results in their respective research works as they found a decline in the AA after about 60 minutes of alcohol ingestion. These changes in the ocular media brought by ingestion of fresh palm wine alcoholic beverage could be because on an empty stomach, alcohol is readily absorbed into the blood within 5-10 minutes of ingestion ${ }^{[23]}$. The peak period of alcohol in the blood is usually from 30-90 minutes. This could explain why there was a significant change in pupil size and AA after 90 minutes of intake of fresh palm wine.

TABLE 1 STATISTICAL DATA OF AGE AND WEIGHT OF SUBJECTS

\begin{tabular}{|l|l|l|l|l|l|l|}
\hline Parameter & Minimum value & Maximum value & Mean & S.E.M & S.D & Variance \\
\hline Weight $(\mathrm{kg})$ & 48 & 79 & 61.18 & 1.13 & 8.00 & 64.03 \\
\hline Age & 20 & 34 & 23.46 & 0.36 & 2.54 & 6.44 \\
\hline \multicolumn{4}{|l}{ S.E.M = Standard error of mean. S.D Standard Deviation } \\
\hline
\end{tabular}


Ugwoke, G.I. et.al. Effects of ingested fresh palm wine on pupil diameter and amplitude of accommodation in young adults.

TABLE 2 STATISTICAL DATA SHOWING PUPIL DIAMETER BEFORE AND AFTER FRESH PALM WINE INTAKE.

\begin{tabular}{|l|l|l|l|l|l|l|}
\hline Pupil Diameter & Minimum value & Maximum value & Mean & S.E.M & S.D & Variance \\
\hline Before & 3 & 5 & 3.80 & 0.07 & 0.72 & 0.52 \\
\hline After & & & & & & \\
\hline $30 \mathrm{mins}$ & 2 & 4 & 3.30 & 0.06 & 0.61 & 0.37 \\
\hline $60 \mathrm{mins}$ & 2 & 5 & 3.48 & 0.07 & 0.75 & 0.57 \\
\hline $90 \mathrm{mins}$ & 3 & 5 & 4.20 & 0.06 & 0.64 & 0.40 \\
\hline
\end{tabular}

TABLE 3 STATISTICAL DATA SHOWING AMPLITUDE OF ACCOMMODATION BEFORE AND AFTER FRESH PALM WINE INTAKE.

\begin{tabular}{|l|l|l|l|l|l|l|}
\hline AA & Minim um value & Maximum value & Mean & S.E.M & S.D & Variance \\
\hline Before & 6.00 & 20.00 & 12.16 & 0.52 & 3.66 & 13.40 \\
\hline After & & & & & & \\
\hline 30 mins & 9.00 & 24.00 & 13.86 & 0.47 & 3.31 & 11.00 \\
\hline 60 mins & 6.50 & 20.00 & 10.19 & 0.35 & 2.47 & 6.08 \\
\hline 90 mins & 6.00 & 18.25 & 9.16 & 0.30 & 2.12 & 4.49 \\
\hline
\end{tabular}

Table 4: SPSS data analysis result showing $P$ value for testing of first hypothesis using the one way ANOVA

\begin{tabular}{|l|l|}
\hline Source of Variation & P-value \\
\hline Between groups & 0.00 \\
\hline
\end{tabular}

Table 5: SPSS data analysis result showing $P$ value for testing of second hypothesis using the one way ANOVA

\begin{tabular}{|l|l|}
\hline Source of Variation & P-value \\
\hline Between groups & 0.00 \\
\hline
\end{tabular}

\section{Acknowledgement: None}

\section{Conflict of Interest: None}

\section{Source of Funding: None}

\section{Ethical Approval: Approved}

\section{REFERENCES}

1. Obire, O. (2005). Activity of Yeast Species in Palm Sap obtained from three areas in Edo State, Nigeria. Journal of Applied Science Environmental Management, 9: 2530

2. Karamoko, D., Djeni, N.T., N'guessan, K.F., Bouatenin, K.M-P., andDje, K.M. (2012). The Biochemical and microbiological quality of palm wine samples produced at different periods during tapping and changes which occurred during their storage. Food Control, 26(2): 504-511

3. Ezeagu, I.E., Fafunso, M.A., and Ejezie, F.E. (2003). Biochemical Constituents of Palm wine. Ecology of Food and Nutrition, 42: $255-264$

4. Amoa-Awua, W.K., Sampson, E. and Tanodebrah, K. (2007). Growth of yeasts, lactic and acetic acid bacteria in Palm wine during tapping and fermentation from felled oil palm (Elaeisguineensis) in Ghana. Journal of Applied Microbiology, 102: 599-606
5. Aniekpeno, E. and Ojimelukwe, P. (2013). Use of Botanicals in Palm wine Preservation: The case of Sacoglottis gabonensis and Aistonia boonei. Lambert Academic Publisher, 1st Edition, 12

6. Akinrotoye, K.P. (2014). Effects of Fermented Palm wine on some Diarrhoeagenic Bacteria. Journal of Biotechnology and Microbiology, 2(1): 4-14

7. Nwaiwu, O., Ibekwe, V.I., Amadi, E.S., Udebuani, A.C., Nwanebu, F.C., Oguoma, O.I., and Nnokwe, J.C. (2016). Evaluation of Fermentation Products of Palm wine Yeasts and Role of SacoglottisgabonensisSupplement on Products Abundance. Beverages, 2(2): 9

8. Santiago-Urbina, J.A. and Ruiz-Teran, F. (2014). Microbiology and biochemistry of traditional palm wine produced around the world. International Food Research Journal, 21(4): 1261-1269

9. Ibegbulem, C.O., Igwe, C.U., Okwu, G.N., Ujowundu, C.O., Onyeike, E.N. and Ayalogu, E.O. (2013). Total amino acids profiles of heat-processed fresh Elaeis guineensis and Raphia hookeri wines. Food Chemistry, 138(2-3): 1616-1620

10. Ukhun, S.G., Ezeokoli, N.F., and Oyerinde, A.O. (2005) Some Mineral Profile of fresh and bottled palmwine, a comparative study, African journal of Biotechnology. 4(8): 829832

11. Claisse, C., Lewkowicz, D., Cottencin, O., and Nandrino, J.L. (2016). Over Activation of the Pupillary Response to Emotional Information in Short- and - Long-Term Alcohol Abstinent Patients. Alcohol and Alcoholism, 51(626): 670-676

12. Kvamme, T.L., Pedersen, M.U., Overgaard, M., Thomsen, K.R., and Voon, V. (2019). Pupillary Reactivity to Alcohol Cues as a Predictive Biomarker of Alcohol Relapse 
Ugwoke, G.I. et.al. Effects of ingested fresh palm wine on pupil diameter and amplitude of accommodation in young adults.

Following Treatment in a Pilot Study. Journal of Psychopharmacology, 236(4): $1233-1243$

13. Torres, A and Hout, M (2019). Pupil: A window into the mind. Frontiers for young minds $7(3)$

14. Olive, M. and Anikin, A. (2018). Pupil dilation reflects the time course of emotion recognition in human vocalizations. Scientific reports, 8: 4871

15. Azuamah, Y.C., Nwadinigwe, N.J., Esenwah, E.C., Bazuaye, K.N., Agu, G.C., and Nwala, O.R. (2014). Effect of Alcoholic Red wine on the Amplitude of Accommodation of Young Adult. International Journal of Research, 1(11):1541- 1546

16. Spector, R.H. (1990). The Pupils: In Walker, H.K., hall, W.D., Hurst, J.W. Clinical Methods: The History, Physical and Laboratory Examinations. 3rd Edition. Boston:Butterworths; Chapter 58.

17. Lopez-Gil, N., Fernandez-Sanchez, V., Thibos, L.N., Bradley, A., and Martin, J. (2011). What is the Amplitude of Accommodation of an Aberrated Eye? Investigative Ophthalmology and Visual Science, 52(14): 837

18. Iyamu, E., Iyamu, J.E., and Oghovwerha, L. (2012). Anthropometry, Amplitude of Accommodation and spherical Equivalent Refractive error in a Nigerian Population. Ophthalmology, 4(1): 234-239

19. Burns, D.H., Evans, B.J.W., and Allen, P.M. (2014). Clinical Measurement of Amplitude of Accommodation: A Review. Optometry in Practice, 15(3): 75-86

20. Hart, W. (1992). Adler's Physiology of the Eye. 9th Edition. Mosby Year Book: St Louis. 128-129
21. Sergienko, N.M., and Nikonenko, D.P. (2015). Measurement of Amplitude of Accommodation in Young Persons. Clinical and Experimental Optometry, 98(4)

22. Megwas, A.U., Ikoro, N.C., and Ihekaire, D.E. (2012) A comparative study of the effect of Palmwine and beer on Accommodative Tests of Young Adults. Journal of Nigerian Optometric Association. 17 (1): 33-36

23. Zakhari, S. (2006). Overview: How is Alcohol Metabolized by the Body? Alcohol Research and Health, 29(4): 245-254

24. Igwe, S.A., Nwobodo, N., Agbata, C.A. and Obioha, I.C. (2015). Ocular Dynamics of Bolus Ingestion of Eleisguineensis Sap (Palm wine) among Visually Active Volunteers. Journal of Health and visual Sciences, 17(1): 155-161

25. Giulani, B., Obie, L., Peterson, C. and Presley, D. (1977). The effects of ethanol on Intraocular pressure, Blood pressure, and the BP/IOP ratio and a comparison of a Semi-Automated Sphygmomanometer with a conventional Sphygmomanometer. College of Optometry. 455. https://commons.pacifical.edu/opt/455.

26. Castro, J.J., Antonio, M., Rubino, M., Anera, R.G., and Jimenez del Barco, L. (2014). Retinal-Image quality and Night vision performance after alcohol consumption. Journal of Ophthalmology, 4: $1-7$

How to cite this article: Ugwoke, G.I., Esenwah, E.C., Ikoro, N.C. et.al. Effects of ingested fresh palm wine on pupil diameter and amplitude of accommodation in young adults. Int $J$ Health Sci Res. 2021; 11(9): 203-208. DOI: https://doi. org/10.52403/ijhsr.20210932 